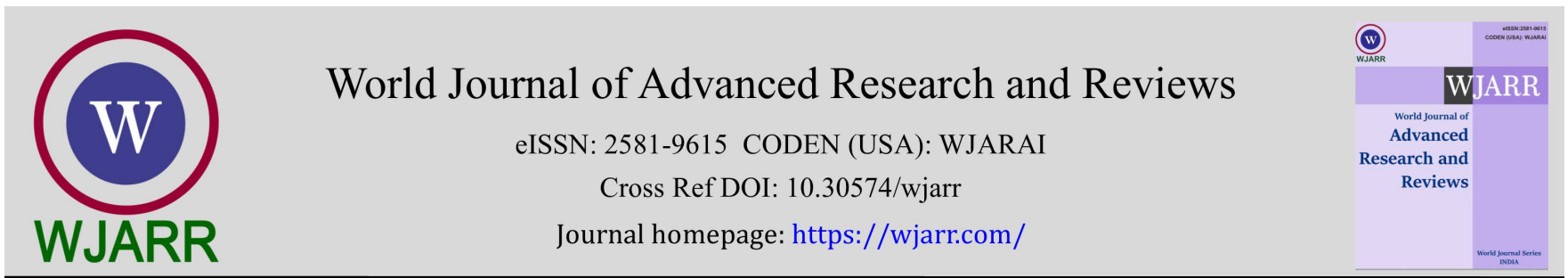

(RESEARCH ARTiCle)

Check for updates

\title{
Effects of sleeve gastrectomy versus omega-loop gastric bypass. What is best for weight loss, perioperative adverse events, and comorbidities?
}

\author{
Omar Thaher ${ }^{1,}{ }^{*}$, Jamal Driouch ${ }^{1}$, Martin Hukauf ${ }^{2}$ and Christine Stroh ${ }^{3}$ \\ ${ }^{1}$ Department of Surgery, Marien Hospital Herne, Ruhr-Universität Bochum, Hölkeskampring 40, 44625 Herne, Germany. \\ 2 StatConsult Society for Clinical and Health Services Research mbH, Am Fuchsberg 11, 39112 Magdeburg, Germany. \\ ${ }^{3}$ Department of General, Abdominal and Pediatric Surgery, Municipal Hospital, Straße des Friedens 122, 07548 Gera, \\ Germany.
}

World Journal of Advanced Research and Reviews, 2021, 12(02), 219-231

Publication history: Received on 05 October 2021; revised on 07 November 2021; accepted on 09 November 2021

Article DOI: https://doi.org/10.30574/wjarr.2021.12.2.0587

\begin{abstract}
Aim of the study: This study investigated whether Sleeve Gastrectomy (SG) or Omega-Loop-Gastric-Bypass (OAGB) has the best benefit in weight loss, perioperative risk, and remission of comorbidities.

Methods: 29,407 patients after SG and OAGB were included in the German Bariatric Surgery Registry (GBSR). Outcome criteria were perioperative morbidity, perioperative complications, and remission of comorbidities after one year of follow-up.

Results: 15,169 patients had completed 1-year follow-up (770 patients after OAGB and 14,399 after SG). The \%EWL was higher for OAGB than for SG $(70.4 \pm 18.5$ for OAGB and $62.4 \pm 22.6$ for SG; $\mathrm{p}<0.001)$. BMI reduction was also a significant difference in favor of OAGB $\left(17.5 \pm 5.6 \mathrm{~kg} / \mathrm{m}^{2}\right.$ for OAGB vs. $15.5 \pm 5.9$ for SG; $\left.\mathrm{p}<0.001\right)$. There was no significant difference between the two groups in perioperative complications $(p<5 \%)$. Significant differences in favor of OAGB were found in remission of hypertension ( $\mathrm{p}<0.001)$, IDDM $(\mathrm{p}<0.001)$, NIDDM $(\mathrm{p}<0.001)$, reflux $(\mathrm{p}<0.001)$, and sleep apnea $(\mathrm{p}<0.001)$.

Conclusion: Our analysis showed that OAGB surgery was associated with more significant BMI reduction and weight loss one year after surgery. In addition, OAGB surgery was significantly more effective in improving obesity-related comorbidities. Our results support the performance of OAGB over SG in patients with obesity and comorbidities. However, the contraindications and general condition of the patient should be considered in the context of this.
\end{abstract}

Keywords: Sleeve gastrectomy; Omega-Loop-Gastric-Bypass; Follow-up; Perioperative complications; Comorbidities.

\section{Introduction}

Worldwide, more people suffer from extreme obesity every year. Furthermore, the average body mass index (BMI) has been steadily increasing in all genders worldwide, with higher prevalence in developed than in developing countries [1]. In addition to obesity-related diseases such as arterial hypertension, sleep apnea, cancer, and type 2 diabetes mellitus (T2D), obesity causes an economic burden on the health care system and a reduction in life expectancy for patients with obesity [2].

\footnotetext{
* Corresponding author: Omar Thaher

Department of Surgery, Marien Hospital Herne, Ruhr-Universität Bochum, Hölkeskampring 40, 44625 Herne, Germany.

Copyright (@ 2021 Author(s) retain the copyright of this article. This article is published under the terms of the Creative Commons Attribution Liscense 4.0.
} 
Despite the benefits of conservative therapy for obese patients, several clinical trials have shown a major advantage of bariatric and metabolic surgery over other pharmacological therapeutic modalities [3]. This effect was also particularly notable in terms of weight loss and remission of comorbidities [4]. Despite these advantages of bariatric surgery, it was possible to distinguish between the different bariatric surgical procedures regarding short- and long-term effects and effects on BMI and weight loss in patients with obesity.

Given the topic of this study, two surgical procedures, namely sleeve gastrectomy (SG) and Omega-Loop-Gastric-Bypass (OAGB) are compared. Several clinical studies have shown different results regarding the two procedures' short- and long-term effects [5]. Despite the described advantages of OAGB and the positive effects of this procedure on weight loss and remission of comorbidities compared with other bariatric procedures [6; 7], some points, such as the patient's medical history, the goal of the procedure, should be considered before choosing this type of intervention. This is also true for SG. Despite the safety of SG regarding the surgical technique, short-and long-term efficiency, SG has shown disadvantages compared to other surgical procedures [8].

Based on data from the German Bariatric Surgery Registry (GBSR), our study aims to present the short- and mid-term outcomes of sleeve gastrectomy and omega-loop gastric bypass in terms of perioperative outcomes, weight loss, and improvement of comorbidities.

\section{Material and methods}

All analyses were performed using SAS 9.4 software (SAS Institute Inc, Cary, NC, USA). Because this is an exploratory analysis, there is no correction for multiple testing, and any p-value $<=0.05$ corresponds to a significant result. This study focuses solely on perioperative outcomes and one-year follow-up of OAGB and SG as primary interventions.

\subsection{Patients and selection criteria}

Our analysis included various medical aspects, such as comorbidities, demographic distribution, and duration of surgery. In addition, the specific postoperative complications such as sepsis, abscess formation, bleeding requiring transfusion, and bleeding requiring surgery were studied. Intraoperative complications were analyzed, such as splenic, biliary, hepatic, and vascular injuries, pneumothorax, gastric perforation, and intraoperative bleeding. In a first step, we compared the short-term outcome of patients after OAGB $(n=1553)$ with those who underwent primary SG $(n=$ $27,854)$. In a second step, we analyzed the one-year follow-up results of both procedures $(n=770$ after $0 A G B$ and 14,399 after SG). The indication for OAGB or SG was not standardized and was not documented in our study. In addition, because this is a registry data collection, we cannot describe the surgical steps for OAGB and SG. It depends on the surgeons and their experience.

The following criteria were considered in the present study:

- $\quad$ Patients with obesity and a valid age of at least 18 years $(n=73,228)$.

- $\quad$ Patients with obesity and primary surgery $(n=63,787)$.

- $\quad$ Patients with obesity and primary OAGB or SG $(n=29,407)$.

- Patients with obesity at one-year follow-up (182 to 547 days after surgery) $(n=15,169)$.

We extracted the following data from the German Bariatric Surgery Registry (GBSR).

\subsection{Data preparation}

The individual target variables are not explicitly recorded but must be derived from the data. These refer to:

- Weight loss: the difference between weight at baseline and weight at follow-up.

- $\quad$ BMI reduction: the difference between BMI at baseline and BMI at follow-up.

- \%EWL: ratio of weight loss to excess weight as a percentage, where excess weight is defined as the difference between weight and ideal weight (based on height and BMI = 25) at baseline.

- Comorbidities, intraoperative, general, and specific postoperative complications are recorded individually and aggregated into one variable, e.g., intraoperative complications are reported if at least one intraoperative complication is selected.

- Follow-up period: 1 year considering a visit window of 182 to 547 days after surgery. 


\subsection{Descriptive statistics}

For the distributions of (quasi-) continuous variables, mean and standard deviation (STD) or, in the case of roottransformed data, mean and range (because the range after inverse transformation is not symmetrical to the mean) and the number of patients included in the analysis (N) are reported. Absolute (N) and relative (\%) frequencies are presented in contingency tables for categorical variables. However, it should be noted that the means from the original data and after back transformation are not identical.

\subsection{Univariates / unadjusted analyses}

Unadjusted analysis (for other variables) means that several influencing variables are not considered simultaneously. The focus here is on the univariate comparison of surgical procedures. Analysis of categorical outcomes was performed using the chi-square test. For continuous results, a robust t-test (Satterthwaite) was used. When the distribution was significantly different from the normal distribution (duration of surgery), a root function transformation to approximate a normal distribution was used to perform the test.

\section{Results}

We analyzed data from 15,169 patients from January 2005 to April 2021 who completed a one-year follow-up period after primary SG and OAGB. Over $98 \%$ of both procedures were performed laparoscopically. For this reason, we did not include the effect of this type of surgery in our analysis. However, the switch from laparoscopy to laparotomy was reported to be significantly more frequent in OAGB than in SG. The operating time was significantly longer at OAGB (mean $94.8 \mathrm{~min}$ ) than at SG (78.9 min; p<0.001) (Table 1; 2; Figure 1).

Table 1 Distribution of surgical method and type at the time of primary surgery and at one-year follow-up

\begin{tabular}{|l|c|c|c|c|}
\hline & \multicolumn{2}{|c|}{ At time of primary surgery } & \multicolumn{2}{c|}{ At one-year follow-up } \\
\hline & $\mathbf{N}$ & $\mathbf{\%}$ & $\mathbf{N}$ & $\mathbf{\%}$ \\
\hline OAGB & 1553 & 5.3 & 770 & 5.1 \\
\hline SG & 27854 & 94.7 & 14399 & 94.9 \\
\hline Total & 29407 & 100 & 15169 & 100 \\
\hline
\end{tabular}

Table 2 Distribution of surgery types for patients who had completed one-year follow-up

\begin{tabular}{|c|c|c|c|c|c|c|}
\hline & \multicolumn{2}{|c|}{ SG } & \multicolumn{3}{|c|}{ OAGB } \\
\hline & & $\mathbf{n}$ & $\%$ & $\mathbf{n}$ & $\%$ & p-value \\
\hline \multicolumn{2}{|l|}{ Laparotomy } & 89 & 0.6 & 6 & 0.8 & \multirow[t]{3}{*}{$<0.001$} \\
\hline \multicolumn{2}{|l|}{ Laparoscopy } & 14231 & 99.1 & 755 & 98.1 & \\
\hline \multicolumn{2}{|l|}{ Conversion } & 46 & 0.3 & 9 & 1.2 & \\
\hline Operating time (min) & N/mean/STD & \multicolumn{2}{|c|}{$\begin{array}{c}14356 / 78.9 \\
{[74.7 ; 83.0]}\end{array}$} & \multicolumn{2}{|c|}{$\begin{array}{c}770 / 94.8 \\
{[90.6 ; 99.1]}\end{array}$} & $<0.001$ \\
\hline
\end{tabular}

\subsection{Demographic Data}

Patients with OAGB were older than those in the SG group $(45.2 \pm 10.9$ years in OAGB vs. $43.7 \pm 11.4$ years in SG; $\mathrm{p}<0.001)$ but had significantly lower BMI $(50.6 \pm 7.4 \mathrm{~kg} / \mathrm{m} 2$ in OAGB vs. $51.3 \mathrm{~kg} / \mathrm{m} 2$ in $\mathrm{SG} ; \mathrm{p}<0.001)$. The gender distribution was significantly different in the two groups. The proportion of females was significantly higher than males in both groups ( $74.4 \%$ female vs. $25.6 \%$ male in OAGB and $67.1 \%$ female vs. $32.9 \%$ male in SG; $<<0.001$ ). The continuous parameters of the perioperative course for all patients who underwent SG and OAGB are shown in Table 3.

Table 3 Distribution of demographic variables at the time of surgery 
World Journal of Advanced Research and Reviews, 2021, 12(02), 219-231

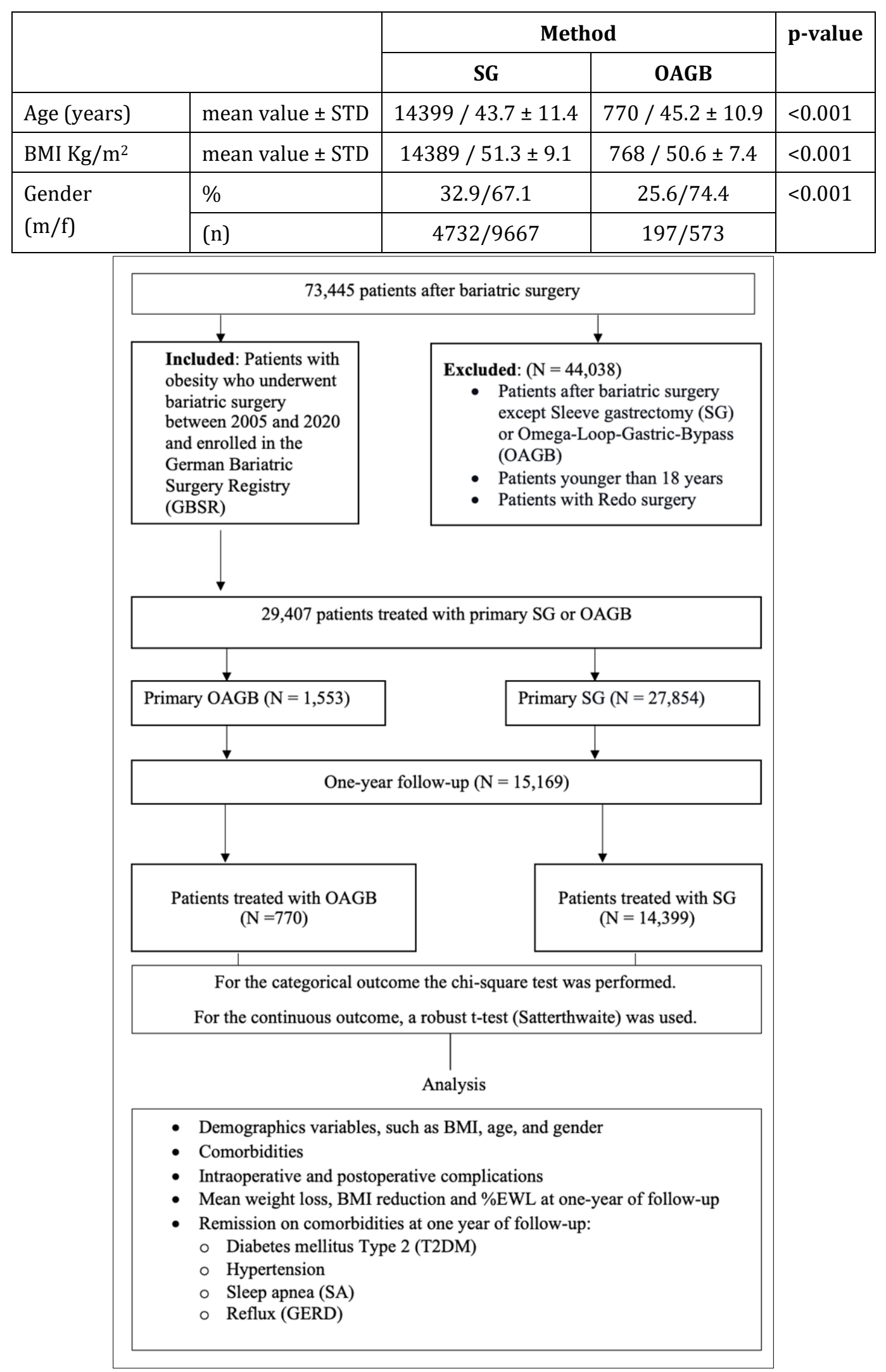

Figure 1 Flowchart of patient inclusion

\subsection{Comorbidities}


A summary of the distribution of comorbidities is given in Table 4. The percentage distribution of comorbidities was significantly higher in the OAGB group $(96.4 \%)$ than in the SG group $(92 \% ; \mathrm{p}<0.001)$. The ASA classification was distributed differently between the two groups. While ASA III was significantly more frequently documented in the OAGB group ( $57.7 \%$ vs. $52.3 \%$ ), ASA IV was more frequent in the SG group $(2.2 \%$ vs. $1.8 \%$; $\mathrm{p}<0.001)$.

The distribution of comorbidities (T2d, hypertension, reflux, and sleep apnea) was significantly higher in the OAGB group than in the SG group.

Table 4 Distribution of comorbidities

\begin{tabular}{|c|c|c|c|c|c|c|}
\hline & \multicolumn{4}{|c|}{ Method } & \multirow[t]{3}{*}{ p-value } \\
\hline & & \multicolumn{2}{|c|}{ SG } & \multicolumn{2}{|c|}{ OAGB } & \\
\hline & & $\mathbf{n}$ & $\%$ & $\mathbf{n}$ & $\%$ & \\
\hline \multirow[t]{4}{*}{ ASA } & ASA I & 585 & 4.1 & 3 & 0.4 & \multirow[t]{4}{*}{$<0.001$} \\
\hline & ASA II & 5952 & 41.4 & 308 & 40.1 & \\
\hline & ASA III & 7525 & 52.3 & 444 & 57.7 & \\
\hline & ASA IV & 314 & 2.2 & 14 & 1.8 & \\
\hline \multirow[t]{2}{*}{ Comorbidities (total) } & Yes & 13244 & 92.0 & 742 & 96.4 & \multirow[t]{2}{*}{$<0.001$} \\
\hline & No & 1155 & 8.0 & 28 & 3.6 & \\
\hline \multirow[t]{2}{*}{ Diabetes (total) T2D } & Yes & 4427 & 33.3 & 312 & 43.1 & \multirow[t]{2}{*}{$<0.001$} \\
\hline & No & 8864 & 66.7 & 412 & 56.9 & \\
\hline \multirow[t]{2}{*}{ T2D (IDDM) } & Yes & 1410 & 10.6 & 109 & 15.1 & \multirow[t]{2}{*}{$<0.001$} \\
\hline & No & 11881 & 89.4 & 615 & 84.9 & \\
\hline \multirow[t]{2}{*}{ T2D (NIDDM) } & Yes & 2406 & 18.1 & 157 & 21.7 & \multirow[t]{2}{*}{0.015} \\
\hline & No & 10885 & 81.9 & 567 & 78.3 & \\
\hline \multirow[t]{2}{*}{ T2D (dietary) } & Yes & 611 & 4.6 & 46 & 6.4 & \multirow[t]{2}{*}{0.029} \\
\hline & No & 12680 & 95.4 & 678 & 93.6 & \\
\hline \multirow[t]{2}{*}{ Arterial hypertension } & Yes & 9206 & 63.9 & 526 & 68.3 & \multirow[t]{2}{*}{0.014} \\
\hline & No & 5193 & 36.1 & 244 & 31.7 & \\
\hline \multirow[t]{2}{*}{ Pulmonary } & Yes & 2975 & 20.7 & 166 & 21.6 & \multirow[t]{2}{*}{0.549} \\
\hline & No & 11424 & 79.3 & 604 & 78.4 & \\
\hline \multirow[t]{2}{*}{ Pulmonary embolism } & Yes & 166 & 1.2 & 2 & 0.3 & \multirow[t]{2}{*}{0.021} \\
\hline & No & 14233 & 98.8 & 768 & 99.7 & \\
\hline \multirow{2}{*}{$\begin{array}{l}\text { Other cardiac and vascular } \\
\text { diseases (OCVD) }\end{array}$} & Yes & 1562 & 10.8 & 69 & & \multirow[t]{2}{*}{0.100} \\
\hline & No & 12837 & 89.2 & 701 & 91.0 & \\
\hline \multirow[t]{2}{*}{ Cholecystolithiasis } & Yes & 530 & 3.7 & 58 & 7.5 & \multirow[t]{2}{*}{$<0.001$} \\
\hline & No & 13869 & 96.3 & 712 & 92.5 & \\
\hline Reflux & Yes & 1590 & 11.0 & 194 & 25.2 & $<0.001$ \\
\hline & No & 12809 & 89.0 & 576 & 74.8 & \\
\hline Lymphedema & Yes & 891 & 6.2 & 52 & 6.8 & 0.527 \\
\hline & No & 13508 & 93.8 & 718 & 93.2 & \\
\hline Degenerative diseases of the & Yes & 6894 & 47.9 & 478 & 62.1 & $<0.001$ \\
\hline skeletal system (DSD) & No & 7505 & 52.1 & 292 & 37.9 & \\
\hline Orthopedic therapy & Yes & 3978 & 27.6 & 216 & 28.1 & 0.797 \\
\hline & No & 10421 & 72.4 & 554 & 71.9 & \\
\hline Degenerative spine diseases & Yes & 5163 & 35.9 & 281 & 36.5 & 0.720 \\
\hline & No & 9236 & 64.1 & 489 & 63.5 & \\
\hline Gonarthrosis & Yes & 3500 & 24.3 & 190 & 24.7 & 0.817 \\
\hline
\end{tabular}


World Journal of Advanced Research and Reviews, 2021, 12(02), 219-231

\begin{tabular}{|c|c|c|c|c|c|c|}
\hline & No & 10899 & 75.7 & 580 & 75.3 & \\
\hline \multirow[t]{2}{*}{ Coxarthrosis } & Yes & 902 & 6.3 & 55 & & \multirow[t]{2}{*}{0.329} \\
\hline & No & 13497 & 93.7 & 715 & 92.9 & \\
\hline \multirow[t]{2}{*}{ Smoking } & Yes & 1380 & 9.6 & 66 & 8.6 & \multirow[t]{2}{*}{0.351} \\
\hline & No & 13019 & 90.4 & 704 & 91.4 & \\
\hline \multirow[t]{2}{*}{ Varicosis } & Yes & 775 & 5.4 & 37 & 4.8 & \multirow[t]{2}{*}{0.488} \\
\hline & No & 13624 & 94.6 & 733 & 95.2 & \\
\hline \multirow{2}{*}{$\begin{array}{l}\text { Non-Alcoholic } \quad \text { Steatohepatitis } \\
\text { (NASH) }\end{array}$} & Yes & 599 & 5.4 & 85 & 11.7 & \multirow[t]{2}{*}{$<0.001$} \\
\hline & No & 10594 & 94.6 & 640 & 88.3 & \\
\hline \multirow[t]{2}{*}{ Alcohol } & Yes & 52 & 2.5 & 193 & 1.3 & \multirow[t]{2}{*}{$<0.001$} \\
\hline & No & 1990 & 97.5 & 14206 & 98.7 & \\
\hline \multirow[t]{2}{*}{ Pseudotumor Cerebri } & Yes & 33 & 0.3 & 1 & 0.1 & \multirow[t]{2}{*}{0.443} \\
\hline & No & 11160 & 99.7 & 724 & 99.9 & \\
\hline \multirow{2}{*}{$\begin{array}{ll}\text { Rheumatoid } & \text { inflammatory } \\
\text { diseases (RID) } & \\
\end{array}$} & Yes & 153 & 1.4 & 11 & 1.5 & \multirow[t]{2}{*}{0.737} \\
\hline & No & 11039 & 98.6 & 714 & 98.5 & \\
\hline \multirow{2}{*}{$\begin{array}{l}\text { Polycystic ovary syndrome } \\
\text { (PCOS) }\end{array}$} & Yes & 174 & 2.3 & 6 & 1.1 & \multirow[t]{2}{*}{0.071} \\
\hline & No & 7391 & 97.7 & 533 & 98.9 & \\
\hline \multirow{2}{*}{$\begin{array}{l}\text { Chronic inflammatory } \\
\text { gastrointestinal diseases }\end{array}$} & Yes & 49 & 0.4 & 0 & 0 & \multirow[t]{2}{*}{0.074} \\
\hline & No & 11143 & 99.6 & 725 & 100 & \\
\hline \multirow[t]{2}{*}{ Hypogonadism } & Yes & 25 & 0.7 & 1 & 0.5 & \multirow[t]{2}{*}{0.806} \\
\hline & No & 3602 & 99.3 & 185 & 99.5 & \\
\hline \multirow[t]{2}{*}{ Transplantation } & Yes & 16 & 0.1 & 0 & 0 & \multirow[t]{2}{*}{0.308} \\
\hline & No & 11176 & 99.9 & 725 & 100 & \\
\hline \multirow[t]{2}{*}{ Sleep apnea } & Yes & 4070 & 28.3 & 302 & 39.2 & \multirow[t]{2}{*}{$<0.001$} \\
\hline & No & 10329 & 71.7 & 468 & 60.8 & \\
\hline
\end{tabular}

\subsection{Intraoperative complications}

There was no significant difference between the two groups in the overall rate of intraoperative complications $(\mathrm{p}=0.610)$. At least one intraoperative complication occurred in 9 patients $(1.2 \%)$ after OAGB and 200 patients $(1.4 \%)$ after SG. With an overall p-value greater than 5\%, analysis of individual complications showed no significant results between the two groups. The details of intraoperative complications are summarized in Table 5.

Table 5 Intraoperative complications reported for Sleeve Gastrectomy and Omega-Loop-Gastric-Bypass

\begin{tabular}{|c|c|c|c|c|c|c|}
\hline & & \multicolumn{4}{|c|}{ Method } & \multirow[t]{3}{*}{ p-value } \\
\hline & & \multicolumn{2}{|c|}{ SG } & \multicolumn{2}{|c|}{ OAGB } & \\
\hline & & $\mathbf{n}$ & $\%$ & n & $\%$ & \\
\hline \multirow[t]{2}{*}{ Intraoperative complication (total) } & Yes & 200 & 1.4 & 9 & 1.2 & \multirow[t]{2}{*}{0.610} \\
\hline & No & 14199 & 98.6 & 761 & 98.8 & \\
\hline \multirow[t]{2}{*}{ Injury of splenic } & Yes & 43 & 0.3 & 3 & 0.4 & \multirow[t]{2}{*}{0.655} \\
\hline & No & 14356 & 99.7 & 767 & 99.6 & \\
\hline \multirow[t]{2}{*}{ Injury of liver } & Yes & 14 & $<0.1$ & 1 & 0.1 & \multirow[t]{2}{*}{0.779} \\
\hline & No & 14385 & $>99.9$ & 769 & 99.9 & \\
\hline \multirow[t]{2}{*}{ Pneumothorax } & Yes & 4 & $<0.1$ & 0 & 0 & \multirow[t]{2}{*}{0.644} \\
\hline & No & 14395 & $>99.9$ & 770 & 100 & \\
\hline
\end{tabular}




\begin{tabular}{|l|c|c|c|c|c|c|}
\hline \multirow{2}{*}{ Perforation of the stomach } & Yes & 10 & $<0.1$ & 0 & 0 & \multirow{2}{*}{0.464} \\
\cline { 2 - 7 } & No & 14389 & $>99.9$ & 770 & 100 & \\
\hline \multirow{2}{*}{ Bile duct injury } & Yes & 1 & $<0.1$ & 0 & 0 & \multirow{2}{*}{0.817} \\
\cline { 2 - 7 } & No & 14398 & $>99.9$ & 770 & 100 & \\
\hline \multirow{2}{*}{ Vascular injury } & Yes & 7 & $<0.1$ & 1 & 0.1 & \multirow{2}{*}{0.339} \\
\cline { 2 - 7 } & No & 14392 & $>99.9$ & 769 & 99.9 & \\
\hline \multirow{2}{*}{ Bleeding } & Yes & 5 & $<0.1$ & 0 & 0 & \multirow{2}{*}{0.605} \\
\cline { 2 - 7 } & No & 14394 & $>99.9$ & 770 & 100 & \\
\hline \multirow{2}{*}{ Other } & Yes & 137 & 1.0 & 4 & 0.5 & \multirow{2}{*}{0.224} \\
\cline { 2 - 6 } & No & 14262 & 99.0 & 766 & 99.5 & \\
\hline
\end{tabular}

\subsection{General and special postoperative complications}

There was no significant disadvantage between the two groups for either general or specific postoperative complications (for general complications the $\mathrm{p}$-value was 0.718 and for specific postoperative complications $\mathrm{p}=0.969$ ). This was also true for the analysis of individual general and specific postoperative complications. With a p-value of over $5 \%$, no significant difference was found between the two groups. A summary of the general and specific postoperative complications can be found in Table 6 .

Table 6 General and special postoperative complications reported for Sleeve Gastrectomy and Omega-Loop-GastricBypass

\begin{tabular}{|c|c|c|c|c|c|c|}
\hline & \multicolumn{4}{|c|}{ Method } & \multirow[t]{3}{*}{ p-value } \\
\hline & & \multicolumn{2}{|c|}{ SG } & \multicolumn{2}{|c|}{ OAGB } & \\
\hline & & $\mathbf{n}$ & $\%$ & $\mathbf{n}$ & $\%$ & \\
\hline \multicolumn{7}{|c|}{ General postoperative complication } \\
\hline \multirow[t]{2}{*}{ Total } & Yes & 580 & 4 & 29 & 3.8 & \multirow[t]{2}{*}{0.718} \\
\hline & No & 13819 & 96 & 741 & 96.2 & \\
\hline \multirow[t]{2}{*}{ Urinary tract infection } & Yes & 101 & 0.7 & 4 & 0.5 & \multirow[t]{2}{*}{0.553} \\
\hline & No & 14298 & 99.3 & 766 & 99.5 & \\
\hline \multirow[t]{2}{*}{ Cardiac complication } & Yes & 50 & 0.3 & 5 & 0.6 & \multirow[t]{2}{*}{0.174} \\
\hline & No & 14349 & 99.7 & 765 & 99.4 & \\
\hline \multirow[t]{2}{*}{ Renal complication } & Yes & 30 & 0.2 & 2 & 0.3 & \multirow[t]{2}{*}{0.762} \\
\hline & No & 14369 & 99.8 & 768 & 99.7 & \\
\hline \multirow[t]{2}{*}{ Pulmonary complication } & Yes & 97 & 0.7 & 7 & 0.9 & \multirow[t]{2}{*}{0.440} \\
\hline & No & 14302 & 99.3 & 763 & 99.1 & \\
\hline \multirow[t]{2}{*}{ Fever } & Yes & 104 & 0.7 & 3 & 0.4 & \multirow[t]{2}{*}{0.283} \\
\hline & No & 14295 & 99.3 & 767 & 99.6 & \\
\hline \multirow{2}{*}{ Thrombosis } & Yes & 14 & $<0.1$ & 0 & 0 & \multirow{2}{*}{0.387} \\
\hline & No & 14385 & $>99.9$ & 770 & 100 & \\
\hline \multirow[t]{2}{*}{ Other } & Yes & 314 & 2.2 & 12 & 1.6 & \multirow[t]{2}{*}{0.246} \\
\hline & No & 14085 & 97.8 & 758 & 98.4 & \\
\hline \multicolumn{7}{|c|}{ Special postoperative complication } \\
\hline \multirow[t]{2}{*}{ Total } & Yes & 490 & 3.4 & 26 & 3.4 & \multirow[t]{2}{*}{0.969} \\
\hline & No & 13909 & 96.6 & 744 & 96.6 & \\
\hline \multirow[t]{2}{*}{ Bleeding requiring transfusion } & Yes & 100 & 0.7 & 3 & 0.4 & \multirow[t]{2}{*}{0.316} \\
\hline & No & 14299 & 99.3 & 767 & 99.6 & \\
\hline \multirow[t]{2}{*}{ Bleeding requiring surgery } & Yes & 175 & 1.2 & 4 & 0.5 & \multirow[t]{2}{*}{0.081} \\
\hline & No & 14224 & 98.8 & 766 & 99.5 & \\
\hline \multirow[t]{2}{*}{ Anastomotic leakage } & Yes & 125 & 0.9 & 11 & 1.4 & 0.108 \\
\hline & No & 14274 & 99.1 & 759 & 98.6 & \\
\hline Anastomotic stenosis & Yes & 7 & $<0.1$ & 1 & 0.1 & 0.339 \\
\hline & No & 14392 & $>99.9$ & 769 & 99.9 & \\
\hline Ileus & Yes & 4 & $<0.1$ & 0 & 0 & 0.644 \\
\hline
\end{tabular}


World Journal of Advanced Research and Reviews, 2021, 12(02), 219-231

\begin{tabular}{|l|l|l|l|l|l|l|}
\hline & No & 14395 & $>99.9$ & 770 & 100 & \\
\hline \multirow{2}{*}{ Abscess formation } & Yes & 69 & 0.5 & 2 & 0.3 & \multirow{2}{*}{0.385} \\
\cline { 2 - 7 } & No & 14330 & 99.5 & 768 & 99.7 & \\
\hline \multirow{2}{*}{ Sepsis } & Yes & 35 & 0.2 & 2 & 0.3 & \multirow{2}{*}{0.927} \\
\cline { 2 - 7 } & No & 14364 & 99.8 & 768 & 99.7 & \\
\hline \multirow{2}{*}{ Wound infection } & Yes & 51 & 0.4 & 6 & 0.8 & 0.060 \\
\cline { 2 - 6 } & No & 14348 & 99.6 & 764 & 99.2 & \\
\hline & Yes & 80 & 0.6 & 2 & 0.3 & 0.275 \\
\cline { 2 - 6 } & No & 14319 & 99.4 & 768 & 99.7 & \\
\hline
\end{tabular}

\section{Results at one-year follow-up}

\subsection{Mean weight loss, \%EWL and BMI reduction}

Significant BMI reduction was more remarkable after OAGB than after SG $\left(15.5 \mathrm{~kg} / \mathrm{m}^{2}\right.$ at SG and $17.5 \mathrm{Kg} / \mathrm{m}^{2}$ at OAGB; $\mathrm{p}<0.001)$. This was also true for percent excess weight loss (\%EWL). This was significantly higher in the OAGB group $(70.4 \pm 18.5)$ compared to $62.4 \pm 22.6$ in the SG group ( $\mathrm{p}<0.001)$. Mean weight loss was also significantly higher after OAGB than after $\mathrm{SG}(\mathrm{p}<0.001)$. Table 7 summarizes the results of the two procedures for BMI reduction, \%EWL, and mean weight loss.

Table 7 BMI reduction, \%EWL, and mean weight loss at one-year follow-up

\begin{tabular}{|l|l|l|l|l|}
\hline \multicolumn{2}{|c|}{} & \multicolumn{2}{|c|}{ Method } & \multirow{2}{*}{-value } \\
\cline { 3 - 5 } \multicolumn{2}{|c|}{} & SG & OAGB & \\
\hline BMI reduction $\left(\mathrm{Kg} / \mathrm{m}^{2}\right)$ & mean value \pm STD & $14291 / 15.5 \pm 5.9$ & $759 / 17.5 \pm 5.6$ & $<0.001$ \\
\hline$\%$ EWL & mean value \pm STD & $14362 / 62.4 \pm 22.6$ & $767 / 70.4 \pm 18.5$ & $<0.001$ \\
\hline Mean weight loss $(\mathrm{kg})$ & mean value \pm STD & $14365 / 45.6 \pm 18.0$ & $768 / 50.5 \pm 16.6$ & $<0.001$ \\
\hline
\end{tabular}

\subsection{Remission of Hypertension}

With a p-value of $<0.001$, a significant remission of hypertension was found between the two groups in favor of OAGB. At baseline, more patients in the OAGB group $(68.3 \%$; $n=526)$ had hypertension than in the SG group $(63.9 \% ; n=$ 9206). After one year, hypertension disappeared in 3384 patients (23.5\%) in the SG group and 244 (31.7\%) in the OAGB group. Furthermore, an increase or recent development of hypertension was reported more frequently in the SG group than in the OAGB group (1\% in SG vs. $0.5 \%$ in OAGB). 5814 patients $(40.4 \%)$ in the SG group and $281(36.5 \%)$ in the OAGB group had no improvement in antihypertensive medication (Table 8).

Table 8 Remission of hypertension, T2D, sleep apnea, and reflux-symptoms at one-year follow-up

\begin{tabular}{|c|c|c|c|c|c|c|}
\hline \multirow{3}{*}{\multicolumn{2}{|c|}{ Remission on obesity-associated diseases }} & \multicolumn{4}{|c|}{ Method } & \multirow[t]{3}{*}{ p-value } \\
\hline & & \multicolumn{2}{|c|}{ SG } & \multicolumn{2}{|c|}{ OAGB } & \\
\hline & & $\mathrm{n}$ & $\%$ & $\mathrm{n}$ & $\%$ & \\
\hline \multirow[t]{4}{*}{ Hypertension } & Complete remission & 3384 & 23.5 & 244 & 31.7 & \multirow[t]{4}{*}{$<0.001$} \\
\hline & De novo development of comorbidity & 140 & 1.0 & 4 & 0.5 & \\
\hline & No change & 5814 & 40.4 & 281 & 36.5 & \\
\hline & No comorbidities before and after surgery & 5052 & 35.1 & 240 & 31.2 & \\
\hline \multirow[t]{4}{*}{ IDDM } & Complete remission & 778 & 5.9 & 89 & 12.3 & \multirow[t]{4}{*}{$<0.001$} \\
\hline & De novo development of comorbidity & 81 & 0.6 & 1 & 0.1 & \\
\hline & No change & 632 & 4.8 & 20 & 2.8 & \\
\hline & No comorbidities before and after surgery & 11791 & 88.8 & 613 & 84.8 & \\
\hline NIDDM & Complete remission & 1695 & 12.8 & 132 & 18.3 & $<0.001$ \\
\hline
\end{tabular}


World Journal of Advanced Research and Reviews, 2021, 12(02), 219-231

\begin{tabular}{|l|l|c|c|c|c|c|}
\hline \multirow{5}{*}{ Reflux } & De novo development of comorbidity & 39 & 0.3 & 2 & 0.3 & \\
\cline { 2 - 6 } & No change & 710 & 5.3 & 25 & 3.5 & \\
\cline { 2 - 6 } & No comorbidities before and after surgery & 10838 & 81.6 & 564 & 78.0 & \\
\cline { 2 - 6 } & Complete remission & 1119 & 7.8 & 159 & 20.7 & \multirow{2}{*}{$<0.001$} \\
\cline { 2 - 6 } & De novo development of comorbidity & 2244 & 15.6 & 75 & 9.8 & \\
\cline { 2 - 6 } & No change & 467 & 3.2 & 35 & 4.6 & \\
\cline { 2 - 6 } & No comorbidities before and after surgery & 10560 & 73.4 & 500 & 65.0 & \\
\hline \multirow{5}{*}{ Sleep apnea } & Complete remission & 1469 & 10.2 & 154 & 20.0 & \multirow{2}{*}{$<0.001$} \\
\cline { 2 - 6 } & De novo development of comorbidity & 120 & 0.8 & 4 & 0.5 & \\
\cline { 2 - 6 } & No change & 2601 & 18.1 & 147 & 19.1 & \\
\cline { 2 - 6 } & No comorbidities before and after surgery & 10200 & 70.9 & 464 & 60.3 & \\
\hline
\end{tabular}

\subsection{Remission of diabetes mellitus type II (T2D)}

At baseline, more patients in OAGB suffered from T2D ( $43.1 \%$ in OAGB vs. 33.3\%; $\mathrm{p}<0.001$ ). Regarding remission of insulin-dependent diabetes mellitus (IDDM) at one year, a significant difference was found between the two groups in favor of OAGB ( $\mathrm{p}<0.001)$. The rate of complete remission of IDDM by OAGB and SG is estimated to be $12.3 \%$ and $5.9 \%$, respectively. In addition, no change in pharmaceutical management and insulin dose of IDDM was observed in $4.8 \%$ after SG and in $2.8 \%$ after OAGB. An increase in IDDM was documented in $0.1 \%$ of patients after OAGB compared with $0.6 \%$ after SG.

Regarding non-insulin-dependent diabetes mellitus (NIDDM), significant results were shown between the two groups in favor of OAGB $(\mathrm{p}<0.001)$. A complete remission rate was documented in $12.8 \%$ after SG and in $18.3 \%$ after OAGB. De novo of NIDDM was documented in $0.3 \%$ after OAGB and $0.3 \%$ after SG. No change was reported by $5.3 \%$ after SG and by 3.5\% after OAGB. Table 8 shows the results of T2D after SG and AGB after one year (Table 8).

\subsection{Remission of gastroesophageal reflux disease (GERD)}

At baseline, 1590 (11\%) patients in the SG group and 194 (25.2\%) patients in the OAGB group suffered from gastroesophageal reflux disease. After one year, 1119 patients (7.8\%) in the SG group and 159 patients (20.7\%) in the OAGB group reported complete remission of reflux symptoms $(\mathrm{p}<0.001)$. In contrast, no change in symptoms was documented more frequently in the OAGB group than in the SG group ( $4.6 \% \mathrm{vs} .3 .2 \%) .9 .8 \%$ of patients after OAGB who had gastroesophageal reflux disease at baseline reported de novo reflux symptoms one year after AGB, whereas this was the case in $15.6 \%$ of patients who underwent $S G(p<0.001)$ (Table 8$)$.

\subsection{Remission of sleep apnea (SA)}

Both groups showed significant changes in sleep apnea symptoms. Complete remission of sleep apnea was more pronounced in the OAGB group than in the SG group ( $20 \%$ in OAGB vs. $10.2 \%$ in SG; $\mathrm{p}<0.001$ ). De novo of symptoms was documented more frequently in the $S G$ group $(0.8 \%$ vs. $0.5 \%)$. However, no change in symptoms was more frequent in the OAGB group than in the SG group (19.1\% vs. 18.1\%) (Table 8).

\section{Discussion}

The present study compares the short- and mid-term outcomes of two bariatric surgical procedures: sleeve gastrectomy and omega-loop gastric bypass. A significant difference was found between the two groups regarding remission of comorbidities, BMI reduction, and weight loss in favor of OAGB. There was no significant difference between the two groups concerning perioperative adverse events.

Several clinical trials have found a positive effect of bariatric surgery on patients with obesity and their quality of life. Despite this overall effect, significant differences in short- and long-term outcomes have been noted between different bariatric surgical procedures [9]. This has also led to some uncertainty in the decision of which surgical procedures should be used. 
Despite our extensive literature search, we did not find enough studies that accurately analyzed and compared the effect and outcome of the two procedures.

OAGB has shown positive results in many studies compared to other bariatric procedures in treating obesity-related diseases, such as T2D, hypertension, reflux, and sleep apnea [10]. Despite the advantages of this procedure and according to the recommendations of various clinical studies, there are many limitations in the use of this surgical method, so other surgical processes should be considered as alternatives.

The efficacy of sleeve gastrectomy has been proven over the past decades. The technical simplicity of the procedure, the limited surgical trauma and short operating time can explain the positive effect of this procedure. Nevertheless, many clinical studies have unfortunately shown a limited long-term effect of the method compared to other surgical methods [11].

It should be noted that (significant) results must always be discussed in context and terms of their relevance. Significant differences in numbers of patients may be obtained for minor cases, especially as this is exploratory without adjustment for multiple levels of testing. Effects are partially visible descriptively but not statistically likely because of the small number of cases.

\subsection{Complications}

Complications after SG and OAGB have been the subject of several studies [12]. However, the distribution of the type of complications differed between the two procedures [13]. Soong et al. [14] have reported similar results regarding perioperative outcomes after SG and OAGB. Based on our literature search, fewer studies compared the two procedures in terms of intraoperative and postoperative complications. There was no significant difference between the two procedures in both the overall complication rate and the analysis of individual complications in the present study. This was also true for general and specific postoperative complications.

\subsection{BMI-reduction and \%EWL}

The present study showed a significant difference in \%EWL between the two procedures, with a higher rate according to OAGB $(\mathrm{p}<0.001)$. This was also true for BMI reduction $(\mathrm{p}<0.001)$ at one-year follow-up. Our results follow the findings in the literature [15]. According to Salvi et al. [10], faster weight loss was reported in the first year after OAGB than after SG. Six years after surgery, weight loss was higher in the OAGB group than in the SG group (84\% vs. 75.5\%).

In contrast, the study by Shivakumar et al. [16] showed no significant difference between the two procedures three years after surgery. Our study and most existing studies see more advantages of OAGB compared to SG. Therefore, OAGB could be considered as the first choice if the goal of surgery is to achieve sufficient weight loss and BMI reduction. Of course, before making a decision, the risks and the patient's medical history should be considered, as well as the contraindications for each surgical procedure.

\subsection{Remission on arterial hypertension}

The treatment of hypertension in obese patients is challenging because conservative therapy is unsuccessful in most cases. For this reason, many studies have focused on the effects of bariatric surgery on the treatment of hypertension. In addition, many studies have analyzed the effects of different bariatric procedures on each other to achieve the best outcomes in patients with obesity. A study by Scavone et al. [17] showed significant results in terms of remission of hypertension after OAGB (93.7\%). Based on his retrospective study, Hussain et al. [18] demonstrated the positive effect of OAGB on remission of hypertension (61\% at one year and 58\% at three years). However, the differential effect of SG versus OAGB on hypertension is controversial in the literature. Seetharamaiah et al. [5] showed no significant difference between the two groups regarding remission of hypertension. In contrast, our study found a significant difference between the two procedures in favor of OAGB. However, even if a one-year follow-up shows acceptable results regarding the evolution and disappearance of hypertension, further studies with more extended follow-up periods should be performed to make a reasonable conclusion about the effect of the two procedures on hypertension.

\subsection{Remission on diabetes mellitus}

Indeed, several studies have recommended that the presence of diabetes mellitus in patients with obesity is a compelling argument to perform metabolic surgery to achieve sufficient remission of the disease [19]. In his study, Vázquez et al. [20] reported 100\% remission of T2D in patients with obesity two years after OAGB. A study by Almuhanna et al. [21] has shown complete remission of T2D in 73.8\% of patients ten years after OAGB. However, the comparison between the different bariatric and metabolic surgical procedures showed different results. Shen et al. [22] 
found a significant difference between SG and OAGB in remission of diabetes mellitus in favor of OAGB. The same result was demonstrated in the study by Vrakopoulou et al. [23]. Improvement of diabetes mellitus was observed more frequently in the OAGB group than in patients after SG.

This is also true for the results of our study: $12.3 \%$ of patients after OAGB had complete remission of IDDM compared with 5.9\% after SG and $18.3 \%$ after OAGB had complete remission of NIDDM compared with $12.8 \%$ after SG. However, it should be noted that the change in diabetes mellitus was reported if there was a change in blood glucose levels or a reduction in medication or insulin use during the follow-up period.

\subsection{Remission on Gastroesophageal reflux disease (GERD)}

The presence of reflux disease limits the decision to perform bariatric surgery. Several studies have shown that the disease continues to worsen or even recurs after surgery [24]. In addition, long-term outcomes varied widely between different methods of bariatric surgery. Despite an intensive literature search, we did not find enough studies comparing the two surgical procedures (SG vs. OAGB). Nehmeh et al. [25] have reported an increase in acid reflux and bile reflux after OAGB, causing conversion surgery most times. Carandina et al. [26] analyzed the short- and long-term outcomes after OAGB in their study. 9.8\% of patients developed bile reflux ten years after surgery. This was also the case with SG [27]. Because of the adverse effects of both procedures on patients with reflux, many studies have suggested switching from SG and OAGB to other surgical procedures, such as RYGB [28].

Our study showed a significant difference in favor of OAGB. However, the results of the two surgical procedures to improve reflux in patients with obesity are not satisfactory.

Therefore, in patients with obesity and reflux, perhaps another method, such as RYGB, should be used if the patient's general condition permits and there is no contraindication to the procedure. If there is a choice between sleeve gastrectomy and OAGB, sleeve gastrectomy should be preferred.

\subsection{Remission on sleep apnea}

Several clinical studies have reported an association between improvement in sleep apnea and metabolic surgery. Depending on the surgical procedures, the outcome and evolution of sleep apnea varied. Neuberg et al. [29] analyzed the effect of OAGB on sleep apnea in their study. Overall, significant improvement in sleep apnea was noted at the time of follow-up. Musella et al. [30] also compared the two surgical procedures in terms of resolution and improvement of sleep apnea. A clear significant difference was found in favor of OAGB vs. SG 12 months after surgery.

Our study shows that OAGB has a significant effect on sleep apnea compared to the group after SG. In addition, more de novo reflux symptoms were documented after SG than after OAGB. Thus, if the choice is between OAGB and sleeve gastrectomy, we believe that OAGB should be chosen as the surgical procedure.

\section{Conclusion}

OAGB and SG are safe and effective in treating patients with obesity. One year after surgery, remission of comorbidities, BMI reduction, and \%EWL were significantly higher after OAGB than after SG. There was no significant difference between the two groups in the incidence of perioperative adverse events.

Based on the results of our study, it can be recommended that the OAGB method be preferred over the SG method when deciding between the two methods. However, we concluded that the indication for either method should be made with careful consideration of the patient's medical history and the long-term goal of surgery.

\section{Compliance with ethical standards}

\section{Acknowledgments}

We would like to thank Mr. Hukauf for his contributions to the statistical analysis of our data.

\section{Disclosure of conflict of interest}

Martin Hukauf was employed by the company StatConsult mbH, Magdeburg. The remaining authors declare that they have no competing interest. 


\section{Statement of ethical approval}

For this type of retrospective study, no formal consent was required. All data were gathered and analyzed in accordance with the privacy and ethical standards of the institutional and national research committee and with the 1964 Helsinki declaration and its later amendments or comparable ethical standards.

\section{Statement of informed consent}

Informed consent was obtained from all individual participants included in the study.

\section{Data availability statement}

We extracted the data from the German Bariatric Surgery Registry (GBSR). Data available on request due to privacy/ethical restrictions.

\section{References}

[1] Cefalu WT, Bray GA, Home PD, et al. Advances in the Science, Treatment, and Prevention of the Disease of Obesity: Reflections From a Diabetes Care Editors' Expert Forum. Diabetes Care. 2015; 38(8): 1567-1582.

[2] Tremmel M, Gerdtham UG, Nilsson PM, et al. Economic Burden of Obesity: A Systematic Literature Review. Int J Environ Res Public Health. 2017; 14(4): 435.

[3] Bray GA, Heisel WE, Afshin A, et al. The Science of Obesity Management: An Endocrine Society Scientific Statement. Endocr Rev. 2018; 39(2): 79-132.

[4] Wong SK, Kong AP, Mui WL, et al. Laparoscopic Bariatric Surgery: A Five-Year Review. Hong Kong Med J. 2009 Apr; 15(2): 100-9.

[5] Seetharamaiah S, Tantia 0, Goyal G, et al. LSG vs OAGB-1 Year Follow-up Data-a Randomized Control Trial. Obes Surg. 2017; 27(4): 948-954.

[6] Jain M, Tantia 0, Goyal G, et al. LSG vs MGB-OAGB: 5-Year Follow-up Data and Comparative Outcome of the Two Procedures over Long Term-Results of a Randomised Control Trial. Obes Surg. 2021; 31(3): 1223-1232.

[7] Level L, Rojas A, Piñango S, et al. One anastomosis gastric bypass vs. Roux-en-Y gastric bypass: a 5-year followup prospective randomized trial. Langenbecks Arch Surg. 2021; 406(1): 171-179.

[8] Arapis K, Macrina N, Kadouch D, et al. Outcomes of Roux-en-Y gastric bypass versus sleeve gastrectomy in supersuper-obese patients (BMI $\geq 60 \mathrm{~kg} / \mathrm{m} 2$ ): 6-year follow-up at a single university. Surg Obes Relat Dis. 2019; 15(1): 23-33.

[9] Cresci B, Cosentino C, Monami M, et al. Metabolic surgery for the treatment of type 2 diabetes: A network metaanalysis of randomized controlled trials. Diabetes Obes Metab. 2020; 22(8): 1378-1387.

[10] Salvi P, Kosta S, Fobi M, et al. Banded Sleeve Gastrectomy and One Anastomosis Gastric Bypass/Mini-gastric Bypass for Treatment of Obesity: a Retrospective Cohort Comparative Study with 6 years follow-up. Obes Surg. 2020; 30(4): 1303-1309.

[11] Lager CJ, Esfandiari NH, Luo Y, et al. Metabolic Parameters, Weight Loss, and Comorbidities 4 Years After Rouxen-Y Gastric Bypass and Sleeve Gastrectomy. Obes Surg. 2018; 28(11): 3415-3423.

[12] Lee WJ, Almalki OM, Ser KH, et al. Randomized Controlled Trial of One Anastomosis Gastric Bypass Versus RouxEn-Y Gastric Bypass for Obesity: Comparison of the YOMEGA and Taiwan Studies. Obes Surg. 2019; 29(9): 30473053.

[13] Huynh D, Mazer L, Tung R, et al. Conversion of laparoscopic sleeve gastrectomy to Roux-en-Y gastric bypass: patterns predicting persistent symptoms after revision. Surg Obes Relat Dis. 2021; 17(10): 1681-1688.

[14] Soong TC, Lee MH, Lee WJ, et al. Long-Term Efficacy of Bariatric Surgery for the Treatment of Super-Obesity: Comparison of SG, RYGB, and OAGB. Obes Surg. 2021; 31(8): 3391-3399.

[15] Castro MJ, Jimenez JM, Carbajo MA, et al. Long-Term Weight Loss Results, Remission of Comorbidities and Nutritional Deficiencies of Sleeve Gastrectomy (SG), Roux-En-Y Gastric Bypass (RYGB) and One-Anastomosis Gastric Bypass (OAGB) on Type 2 Diabetic (T2D) Patients. Int J Environ Res Public Health. 2020; 17(20): 7644. 
[16] Shivakumar S, Tantia O, Goyal G, et al. LSG vs MGB-OAGB-3 Year Follow-up Data: a Randomised Control Trial. Obes Surg. 2018; 28(9): 2820-2828.

[17] Scavone G, Caltabiano DC, Gulino F, et al. Laparoscopic mini/one anastomosis gastric bypass: anatomic features, imaging, efficacy and postoperative complications. Updates Surg. 2020; 72(2): 493-502.

[18] Hussain A, El-Hasani S. Short- and Mid-term Outcomes of 527 One Anastomosis Gastric Bypass/Mini-Gastric Bypass (OAGB/MGB) Operations: Retrospective Study. Obes Surg. 2019; 29(1): 262-267.

[19] Li M, Zeng N, Liu Y, et al. The Choice of Gastric Bypass or Sleeve Gastrectomy for Patients Stratified by Diabetes Duration and Body Mass Index (BMI) level: Results from a National Registry and Meta-analysis. Obes Surg. 2021; 31(9): 3975-3989.

[20] Vázquez Pelcastre R, Zenteno Martínez DC, Arana Reyes JC, et al. One-anastomosis gastric bypass (OAGB) in patients with BMI $<30 \mathrm{~kg} / \mathrm{m} 2$ and diabetes mellitus type 2 (DM2). Nutr Hosp. 2021.

[21] Almuhanna M, Soong TC, Lee WJ, Chen JC, Wu CC, Lee YC. Twenty years' experience of laparoscopic 1-anastomosis gastric bypass: surgical risk and long-term results. Surg Obes Relat Dis. 2021; 17(5): 968-975.

[22] Shen SC, Lee WJ, Kasama K, et al. Efficacy of Different Procedures of Metabolic Surgery for Type 2 Diabetes in Asia: a Multinational and Multicenter Exploratory Study. Obes Surg. 2021; 31(5): 2153-2160.

[23] Vrakopoulou GZ, Theodoropoulos C, Kalles V, Zografos G, Almpanopoulos K. Type 2 diabetes mellitus status in obese patients following sleeve gastrectomy or one anastomosis gastric bypass. Sci Rep. 2021; 11(1): 4421.

[24] Zarshenas N, Tapsell LC, Batterham M, et al. Changes in Anthropometric Measures, Nutritional Indices and Gastrointestinal Symptoms Following One Anastomosis Gastric Bypass (OAGB) Compared with Roux-en-y Gastric Bypass (RYGB). Obes Surg. 2021; 31(6): 2619-2631.

[25] Nehmeh WA, Baratte C, Rives-Lange C, et al. Acid Reflux Is Common in Patients With Gastroesophageal Reflux Disease After One-Anastomosis Gastric Bypass [published online ahead of print, 2021 Jul 7]. Obes Surg. 2021.

[26] Carandina S, Soprani A, Zulian V, et al. Long-Term Results of One Anastomosis Gastric Bypass: a Single Center Experience with a Minimum Follow-Up of 10 Years. Obes Surg. 2021; 31(8): 3468-3475.

[27] Davrieux CF, Palermo M, Nedelcu M, Nocca D. Reflux After Sleeve Gastrectomy: An Update. J Laparoendosc Adv Surg Tech A. 2021; 31(9): 978-982.

[28] Rayman S, Assaf D, Azran C, et al. Sleeve Gastrectomy Failure-Revision to Laparoscopic One-Anastomosis Gastric Bypass or Roux-n-Y Gastric Bypass: a Multicenter Study. Obes Surg. 2021; 31(7): 2927-2934.

[29] Neuberg M, Blanchet MC, Gignoux B, Frering V. Long-Term Outcomes After One-Anastomosis Gastric Bypass (OAGB) in Morbidly Obese Patients. Obes Surg. 2020; 30(4): 1379-1384.

[30] Musella M, Apers J, Rheinwalt K, et al. Efficacy of Bariatric Surgery in Type 2 Diabetes Mellitus Remission: the Role of Mini Gastric Bypass/One Anastomosis Gastric Bypass and Sleeve Gastrectomy at 1 Year of Follow-up. A European survey. Obes Surg. 2016; 26(5): 933-940. 